\title{
INCORPORATION OF AN EXPLOSIVE CLOUD RISE CODE INTO ARAC'S ADPIC TRANSPORT AND DIFFUSION MODEL
}

\author{
K. T. Foster and R. P. Freis \\ Lawrence Livermore National Laboratory, University of California \\ Livermore, California 94550 \\ J. S. Nasstrom \\ EG\&G Energy Measurements \\ Pleasanton, California 94583
}

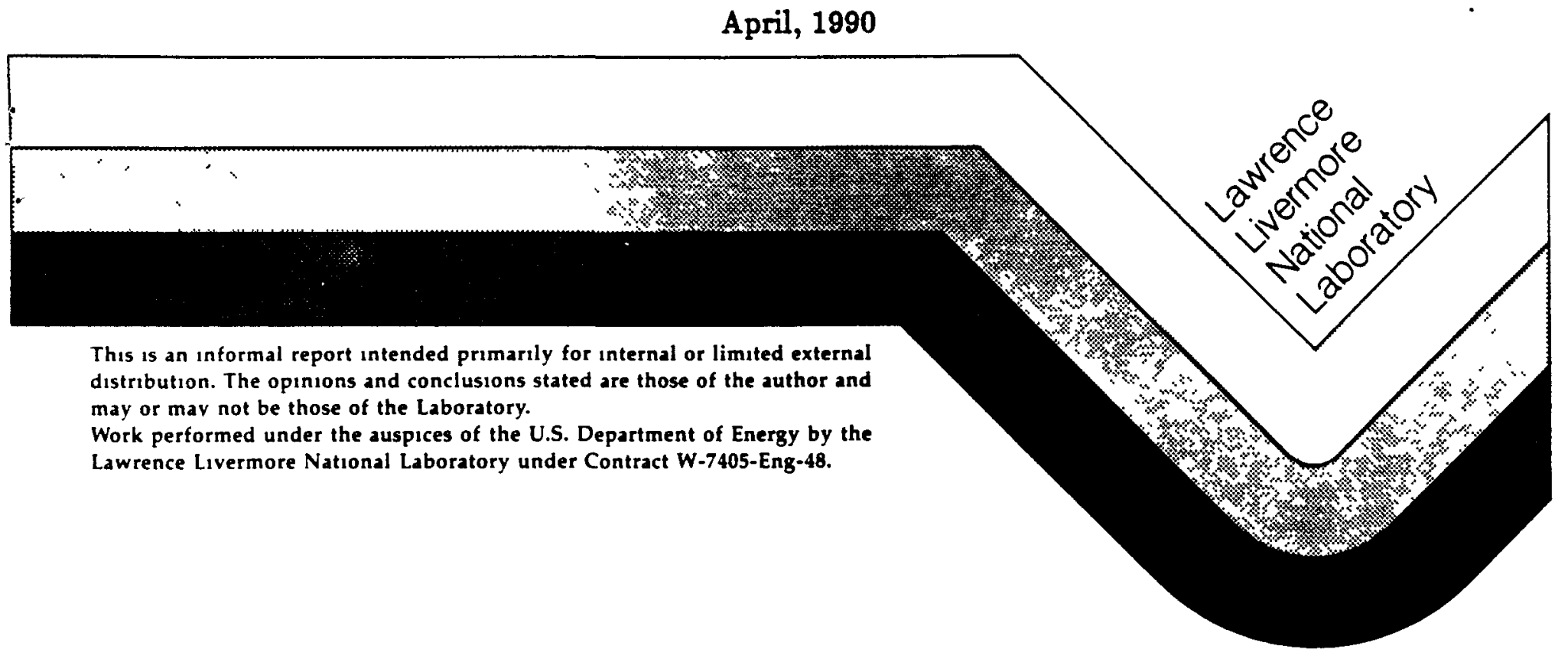




\section{DISCLAIMER}

This report was prepared as an account of work sponsored by an agency of the United States Government. Neither the United States Government nor any agency Thereof, nor any of their employees, makes any warranty, express or implied, or assumes any legal liability or responsibility for the accuracy, completeness, or usefulness of any information, apparatus, product, or process disclosed, or represents that its use would not infringe privately owned rights. Reference herein to any specific commercial product, process, or service by trade name, trademark, manufacturer, or otherwise does not necessarily constitute or imply its endorsement, recommendation, or favoring by the United States Government or any agency thereof. The views and opinions of authors expressed herein do not necessarily state or reflect those of the United States Government or any agency thereof. 


\section{DISCLAIMER}

Portions of this document may be illegible in electronic image products. Images are produced from the best available original document. 


\title{
DISCLAIMER
}

This document was prepared as an account of work sponsored by an agency of the United States Government. Neither the United States Government nor the University of California nor any of their employees, makes any warranty, express or implied, or assumes any legal liability or responsibility for the accuracy, completeness, or usefulness of any information, apparatus, product, or process disclosed, or represents that its use would not infringe privately owned rights. Reference herein to any specific commercial products, process, or service by trade name, trademark, manufacturer, or otherwise, does not necessarily constitute or imply its endorsement, recommendation, or favoring by the United States Government or the University of California. The views and opinions of authors expressed herein do not necessarily state or reflect those of the United States Government or the University of California, and shall not be used for advertising or product endorsement purposes.

\author{
This report has been teproduced \\ directly from the best available copy.
}

Available to DOE and DOE contractors from the

Office of Scientific and Technical Information

P.O. Box 62, Oak Ridge, IN 37831

Prices available from (615) 576-8401, FTS 626-8401.

Available to the public from the

National Technical Information Service

U.S. Department of Commerce

5285 Port Royal Rd.,

Springfield, VA 22161

Price

Code

A01

\section{Papercopy Prices}

$\mathrm{A02}$

A03

A04

A05

A06

A.07

A08

A09

A10

A11

A12

A13

A14

A15

A16

A17

A18

A19

A20

A21

A22

A23

A24

A25

A99
Page

Range

Microfiche 


\section{Introduction}

The U.S. Department of Energy's Atmospheric Release Advisory Capability (ARAC) supports various government agencies by modeling the transport and diffusion of radiological material released into the atmosphere (Dickerson and $\operatorname{Orphan}^{1}$ ). ARAC provides this support principally in the form of computer-generated isopleths of radionuclide concentrations. In order to supply these concentration estimates in a timely manner (15-30 minutes after notification), a suite of operational computer models is maintained by the ARAC staff.

One of the primary tools used by ARAC is the ADPIC transport and diffusion computer model (Lange ${ }^{2}$ ). This three-dimensional, particle-in-cell code simulates the release of a pollutant into the atmosphere, by injecting marker particles into a gridded, mass-consistent modeled wind field. The particles are then moved through the gridded domain by applying the appropriate advection, diffusion, and gravitational fall velocities.

As might be expected, the ADPIC model results are sensitive to the properties assigned to these marker particles during the model initialization. These properties include both individual particle characteristics, such as particle size, and characteristics of the mass of particles taken as a whole, such as the initial geometric distribution of the particles within the calculational grid.

As part of ARAC's operational procedures, a variety of algorithms are employed to derive the initial geometric distribution of the marker particles (if direct measurements or observations of the initial pollutant distribution are not available). The choice of an algorithm is based on the mechanism of release to the atmosphere and knowledge of the physical environment affecting the pollutant's dispersal.

One of the more common release mechanisms is one involving an explosion, in which the resulting thermal environment aerosolizes one or more radionuclides. For example, if the high explosive charge in a nuclear weapon detonates, much of the plutonium in the device is expected to be dispersed in the form of very fine particulate matter. Currently, the initial top of the modeled plutonium cloud is based on the empirical correlation set forth in Church. ${ }^{3}$ This correlation yields the stabilized cloud height based on the amount of chemical explosive (TNT equivalent) that detonated, and does not consider any ambient environmental conditions, such as atmospheric stability, upon the buoyant cloud. To better estimate the distribution of such material immediately following an explosive release, a computer code developed by Sandia National Laboratories (SNL) has been included in the ADPIC model.

\section{The Cloud Rise Code and ADPIC Particle Coupling}

A full description of the SNL explosive cloud rise, integral model code is found in Boughton and Delaurentis. ${ }^{4}$ Briefly, the code provides a time evolution of the physical and thermodynamic properties of a buoyant cloud formed when a chemical explosive is detonated. The model is based on integrating the three-dimensional conservation equations of mass, momentum, and energy over the cloud's cross-section. With some simplifying assumptions, the integral equations reduce to a set of ordinary differential equations, which can be solved for the cloud radius, centerline height, temperature, and velocity as a function 
of time. These solutions are sensitive to the input parameters describing the ambient atmospheric conditions, especially the atmospheric temperature profile. Included in the equations are the effects of buoyancy, entrainment, and pressure drag forces. The cloud is assumed to be a symmetric sphere composed of an equilibrium mixture of dry air and water (which may be present as both vapor and liquid). The initial size and conditions of the cloud are determined using the atmospheric conditions and explosive mass.

Once the cloud's time-dependent characteristics are determined, the coupling of this buoyant volume to the aerosolized source material must be prescribed. This coupling is significantly different in the ADPIC model than in SNL's effort to incorporate cloud rise into a Monte Carlo dispersion model. The following discussion pertains to ARAC's independent effort to address this issue.

There are two considerations in coupling the marker particles to the cloud, the initial loading of the particles into the calculational grid and their subsequent motion while they remain within the buoyant environment. Figure 1 depicts the ADPIC implementation of this coupling. All of the marker particles are initially loaded into the spherical cloud volume at time $t=t o$. They have a Gaussian distribution within this volume with radial cutoff values equal to the initial cloud radius as determined by the cloud model. The standard deviations of this distribution are scaled to the cloud radius and are controlled through a scaling factor used to adjust the "flatness" of the initial distribution. For surface explosions, this initial sphere is tangent to the surface (e.g., it is centered at a height equal to the cloud radius).

As the cloud rises with time, it is assumed to contain an environment of enhanced turbulence with entrainment occurring along its surface. Particles remaining inside the spherical cloud volume are treated differently than those moving beyond the cloud radius. One difference is that ambient diffusion is neglected while particles remain within the buoyant cloud. In addition, a fraction of the cloud's vertical motion is applied to each particle within the cloud radius, $R$. The vertical motion imparted to each particle due to its proximity to the rising cloud is a function of its distance, $r$, from the cloud center, and is given by:

$$
w=W \exp \left[-c(r / R)^{2}\right]
$$

where

$$
\begin{aligned}
w= & \text { the particle's vertical rise velocity } \\
& \text { due to the rising cloud (in addition } \\
& \text { to the vertical advection velocity), } \\
W= & \text { the cloud's vertical rise velocity, } \\
c= & \text { velocity coupling coefficient, } \\
r= & \text { particle's distance from cloud center, and } \\
R= & \text { cloud radius. }
\end{aligned}
$$

Another difference in the treatment of particles within the cloud is a radially outward adjustment to maintain the particle's relative position between the cloud center and cloud edge as the cloud increases in size. This adjustment "velocity" simulates the effects of an expanding, well-mixed cloud by redistributing the particles throughout the entire cloud volume. This velocity due to the cloud's expansion, noted as $\mathbf{V}_{\mathbf{e}}$ in Figure 1 , is independent of the particle's movement relative to the cloud center due to gravitational fall $\left(\mathbf{v}_{\mathbf{g}}\right)$, the 
vertical velocity $w$, and potential differences in advection of the cloud (V) and particles (v) due to the spatial variation in the winds.

Therefore, particles remaining within the extent of the cloud are moved by applying the appropriate advection, expansion, fall, and vertical rise velocities. Once a particle leaves the influence of the rising thermal (usually due to the particle's gravitational fall velocity moving the particle beyond the cloud radius), only the advection, diffusion, and fall velocities are applied.

The dynamics of the cloud are followed until its vertical velocity decreases below a predetermined limit (presently equal to 0.001 meters/second). At this point, all particles are treated as though the cloud no longer exists, and the cloud calculation is bypassed for the remainder of the problem. A similar effect occurs if the cloud center rises above the top of the computational grid.

One of the most significant differences between the ARAC and SNL implementation is the inclusion of the expansion velocity (which is not considered in the SNL coupling). This radially outward velocity causes the particles to be further from the cloud center, where they receive a smaller fractional amount of the cloud's vertical lift (as given by Eqn. 1). This, plus differences in accounting for turbulence effects within the cloud, resulted in a different value of the coupling coefficient, $c$, for the SNL and ARAC implementations. As discussed below, validation tests of this implementation led to an optimized value of 0.35 for the coupling coefficient found in Eqn. 1.

\section{Cloud Rise-ADPIC Validation Studies}

The ADPIC model has undergone numerous validation studies comparing model results to tracer data collected in both simple and complex terrain (Gudiksen et al. ${ }^{5}$ ). The Roller Coaster experiments in 1963 at the Tonopah Test Range in Nevada (Stewart ${ }^{6}$ ) were used to validate the cloud rise code implementation. As described in Gudiksen et al., ${ }^{5}$ the ADPIC model has previously been validated with the Clean Slate 1 data from the Roller Coaster experiments.

Calculations of the cloud-top height alone (with no particle dynamics) were studied first. The accuracy of the time-dependent cloud top calculated by the SNL model has previously been validated using both the Clean Slate 1 and Double Tracks shots from the Roller Coaster series, along with an additional 13 data sets (Boughton and Delaurentis ${ }^{4}$ ). Calculated cloud-top heights were well within a factor of two (usually within 25\%) of the observed values for a range of explosive amounts. (Boughton and Delaurentis, ${ }^{4}$ however, noted that these data sets do not contain a representative case for very unstable atmospheric conditions.)

To test the implementation of the SNL code into ADPIC, the predicted cloud top was compared to the observed cloud heights from both Clean Slate 1 and Double Tracks (Fig. 2). These results are similar to those shown in Boughton and Delaurentis, ${ }^{4}$ and validate that these time-dependent, cloud-top calculations are comparable. Although these results are based on only the time-dependent, buoyant cloud rise formulation (i.e., without considering coupling to ADPIC marker particles), minor differences in the two sets of calculations are 
expected due to the three-dimensional wind field of ADPIC when compared with the twodimensional SNL code.

The complete calculation with ADPIC particles coupled to time-dependent cloud rise was validated using the air concentration and ground deposition measurements of both the Clean Slate 1 and Double Tracks shots. In modeling particle deposition, two dominant physical processes must be adequately described: (1) the fall velocities of the particles, a function of the particle size, and (2) the lift from the thermal cloud affecting the particles. Of critical importance in simulating this second process is the relationship, given by Eqn. 1, between the vertical velocity of the cloud and the vertical velocity of the particles. Figure 3 indicates the sensitivity of the particle rise to the value chosen for the velocity coupling coefficient, $c$, in Eqn. 1. Of the two data sets, Clean Slate 1 appears to be the most complete. The higher percentage of particle capture in downwind measurements led to a relatively well described particle-size distribution. For this reason, Clean Slate 1 data were used to determine the proper value of the velocity coupling coefficient.

The methodology used for the Clean Slate 1 validation is similar to that described in Gudiksen et al. ${ }^{5}$ The important difference is time-dependent cloud rise, which was not used in the earlier calculations. Table 1 summarizes key model parameters used for this study. As in Gudiksen et al., ${ }^{5}$ results are based on a normalized $1 \mathrm{~kg}$ source amount. A series of calculations resulted in an optimized value of 0.35 for the velocity coupling coefficient.

Figure 4 presents these air concentration and deposition results, along with the previous non-cloud-rise ADPIC results from Gudiksen et al. ${ }^{5}$ and the corresponding measured values. The calculated air concentration values generally appear slightly higher than the observations, but remain within a factor of three of the measurements. Of key importance is the significant improvement over previous calculations close to the source (less than one kilometer). Ground deposition calculations show even better agreement with observed values, and an overall improvement over the previous ADPIC results.

To further validate the Cloud Rise-ADPIC combination and the coupling coefficient value of 0.35 , similar comparisons were made for the Double Tracks shot. As in the Clean Slate 1 calculations, these calculations were performed using 10,000 marker particles carrying a normalized $1 \mathrm{~kg}$ of plutonium. Terrain elevation data were used, and terrain effects were included in all aspects of the calculation.

The measured Double Tracks particle-size distribution may not have been representative of the actual size distribution, and several factors were examined before a representative particle-size distribution was determined. One factor considered was that the upper portion of the cloud (approximately $1 / 3$ of the total mass) was not sampled by a downwind, vertical curtain of samplers. Stewart ${ }^{6}$ discusses this and indicates that the unsampled, upper portion of the cloud most likely contained smaller particles than the sampled, lower portion of cloud. Another factor considered was an indication by Stewart ${ }^{6}$ that there may have been two important size distributions in Double Tracks (as well as in other Roller Coaster shots): (a) smaller, primary particulate matter with most of the plutonium mass and a standard geometric deviation of 2 or 3, and (b) larger soil and concrete dust with a small fraction of the total mass and a standard geometric deviation close to 1 . In contrast to Clean Slate 1, the Double Tracks particles would be expected to contain less of the large soil particles since the ground zero soil area was sprayed with a fixative. Unfortunately, 
there were not sufficient data to quantify the two distributions well. However, it is likely that the Double Tracks particle-size distribution contained more mass in smaller particles than either (1) the measured Double Tracks distribution or (2) the measured Clean Slate 1 distribution.

Table 2 presents the two particle-size distributions and other key parameters used in the Double Tracks calculations. The size distributions were different than those of the Clean Slate 1 calculations, but are consistent with the information discussed above. As shown in the table, $99 \%$ of the the Plutonium mass was distributed on particles comprising the smaller size distribution, while the remaining $1 \%$ of the mass was placed on particles of the larger distribution.

Figure 5 presents the comparison of calculated values to the measured air concentration and deposition values. Again, calculations of air concentration generally remain within a factor of three, while deposition results are typically within a factor of two. Other Double Tracks calculations using the Clean Slate 1 size distribution resulted in significant overestimates of air concentration and ground deposition within $3 \mathrm{~km}$ of ground zero. This was due to the larger particle sizes in the Clean Slate 1 distribution resulting in correspondingly larger settling velocities and higher close-in deposition.

\section{Summary}

A cloud rise module has been incorporated into ARAC's ADPIC dispersion model to allow better simulation of particle distribution early after an explosive release of source material. The module is based on the conservation equations of mass, momentum, and energy, which are solved for the cloud radius, height, temperature, and velocity as a funtion of time.

A key relationship is given between the particle rise and cloud rise. During validation studies, a velocity-coupling coefficient used in this relationship is determined through comparisons of model results to the Roller Coaster Clean Slate 1 data set. A coefficient value of 0.35 was found to yield values within a factor of two to three when compared to the Clean Slate 1 air concentration and deposition measurements. Improvements in model prediction were most notable close to the source point (within one kilometer) when compared to a previous ADPIC validation study. Similar accuracy was found for a comparison of model results to Roller Coaster's Double Tracks experiment.

This work was performed under the auspices of the U.S. Department of Energy by the Lawrence Livermore National Laboratory under Contract No. W-7405-Eng-48.

\section{References}

1. Dickerson, M. H., and R. C. Orphan, "Atmospheric Release Advisory Capability," Nuclear Safety, 17, 281-289 (1976).

2. Lange, R.,"ADPIC-A Three-Dimensional Particle-In-Cell Model for the Dispersal of Atmospheric Pollutants and Its Comparison to Regional Tracer Studies," J. Appl. Meteor., 320-329 (1978). 
3. Church, H. W., Cloud Rise from High-Explosive Detonations, Sandia Laboratories, Albuquerque, Report SC-RR-68-903, Health and Safety UC-41, TID-4500, 1969.

4. Boughton, B. A., and J. M. Delaurentis, "An Integral Model of Plume Rise from High Explosive Detonations," 1987 ASME/AIChE National Heat Transfer Conference, August 9-12, 1987, Pittsburgh, PA.

5. Gudiksen, P. H., R. Lange, D. J. Rodriguez, and J. S. Nasstrom, The Use of Field Experimental Studies to Evaluate Emergency Response Models, Lawrence Livermore National Laboratories, Livermore, CA, UCRL-92342, 1985.

6. Stewart, K., Roller Coaster: Summary Report (U), U.K. Atomic Energy Authority Report AWRE No. T6/69 (1969) (Secret). 
$r=$ Distance of Particle From Cloud Center

$\mathrm{R}=$ Radius of Cloud

$\mathbf{w}=$ Vertical Lift of Particle

$W=$ Vertical Lift of Cloud

$v=$ Advection Velocity of Particle

$\mathrm{V}=$ Advection Velocity of Cloud

$\mathrm{V}_{\mathrm{g}}=$ Gravitational Fall Velocity

$V_{\theta}=$ Plume Expansion Velocity

= A Random Particle Within the Cloud

$\boldsymbol{t}=$ Cloud Center

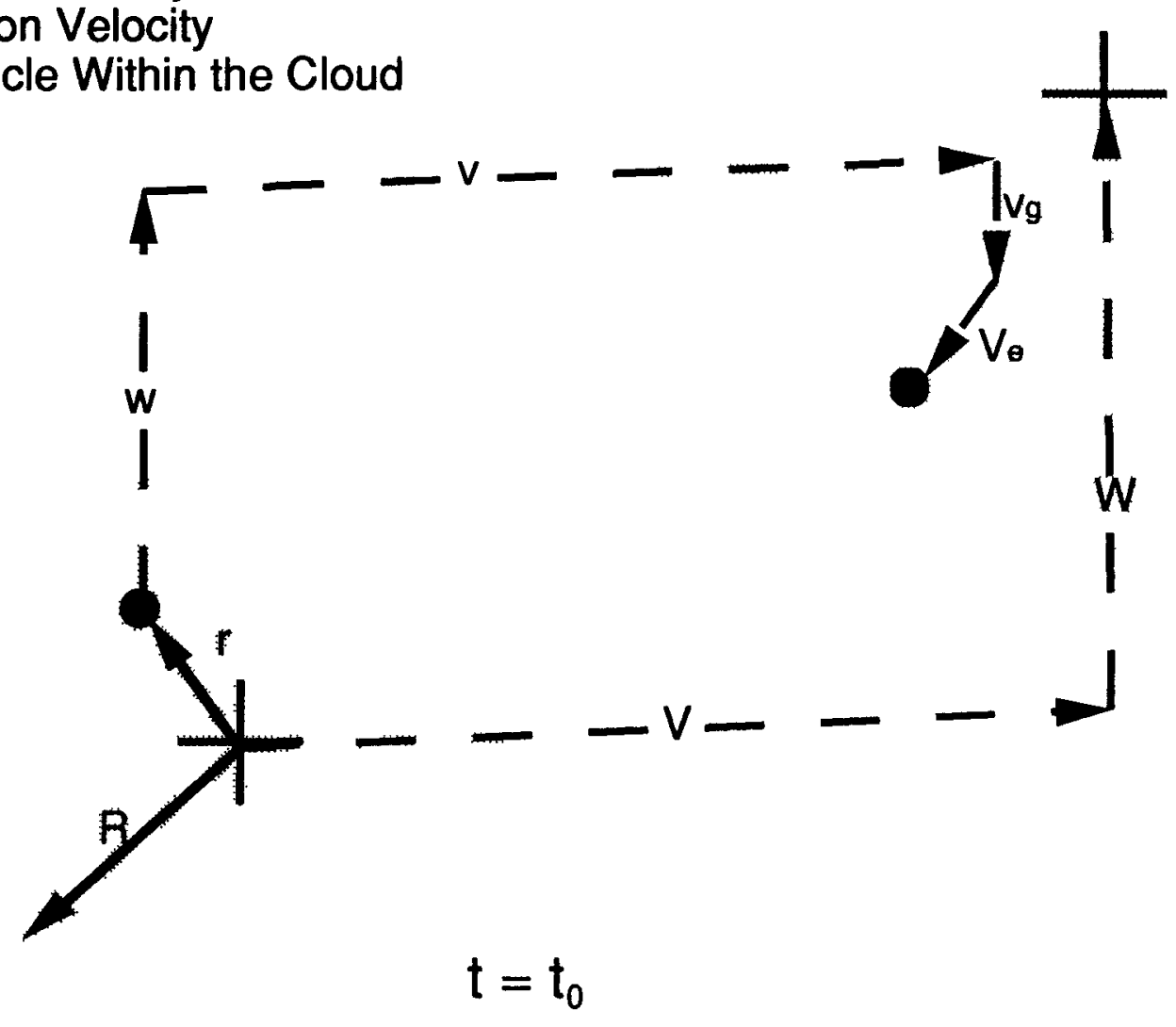

$$
t=t_{0}+\Delta t
$$

\section{Figure 1}

Depiction of velocities applied to the plume and a particle within the plume for the ADPIC implementation 


\section{Clean Slate 1 Cloud Rise}
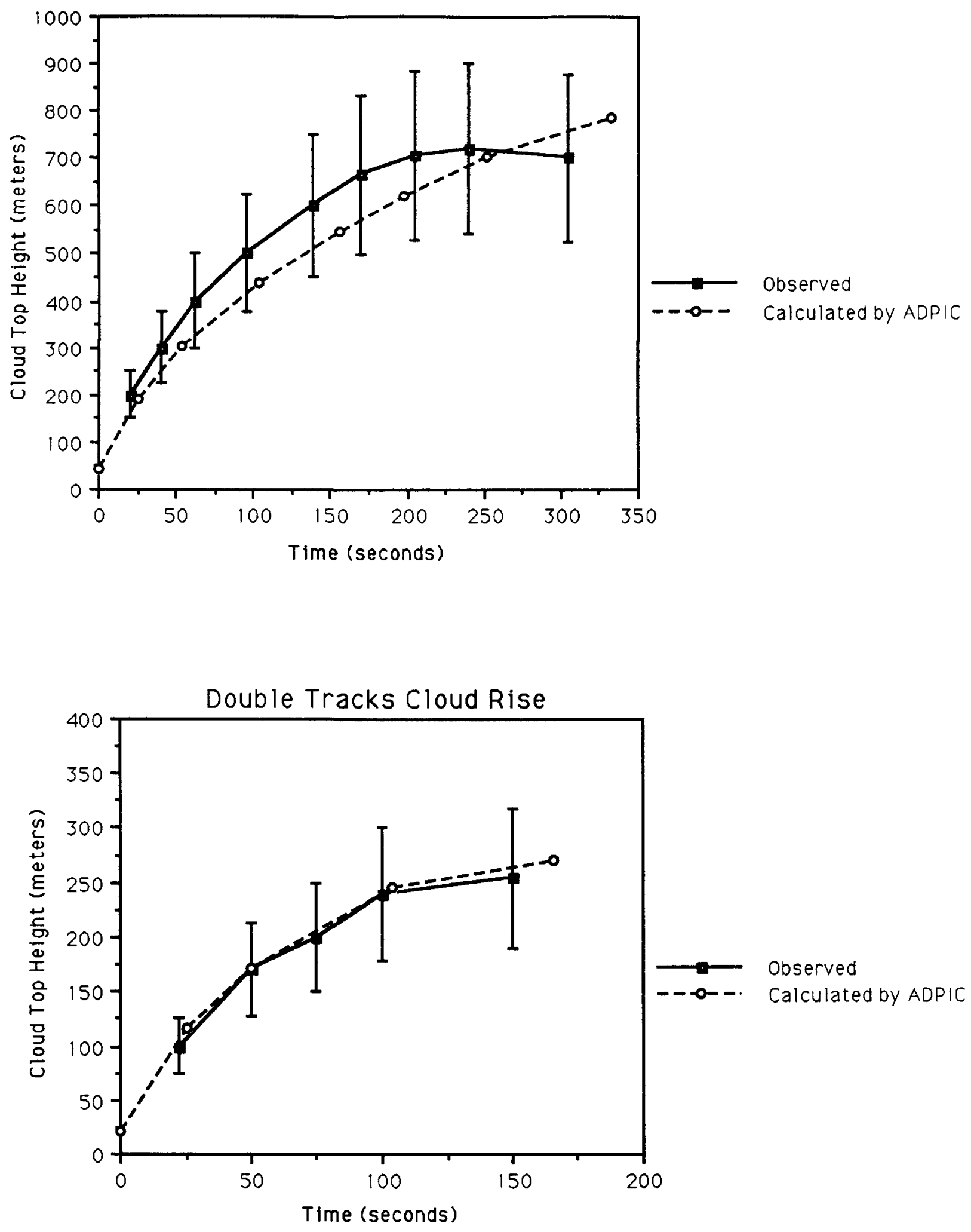

Figure 2: Comparison of Observed and Calculated Cloud Top Heights for Clean Slate 1 and Double Tracks Experiments. (Error Bars are $25 \%$ of Data.) 
Cloud-Particle Velocity Coupling

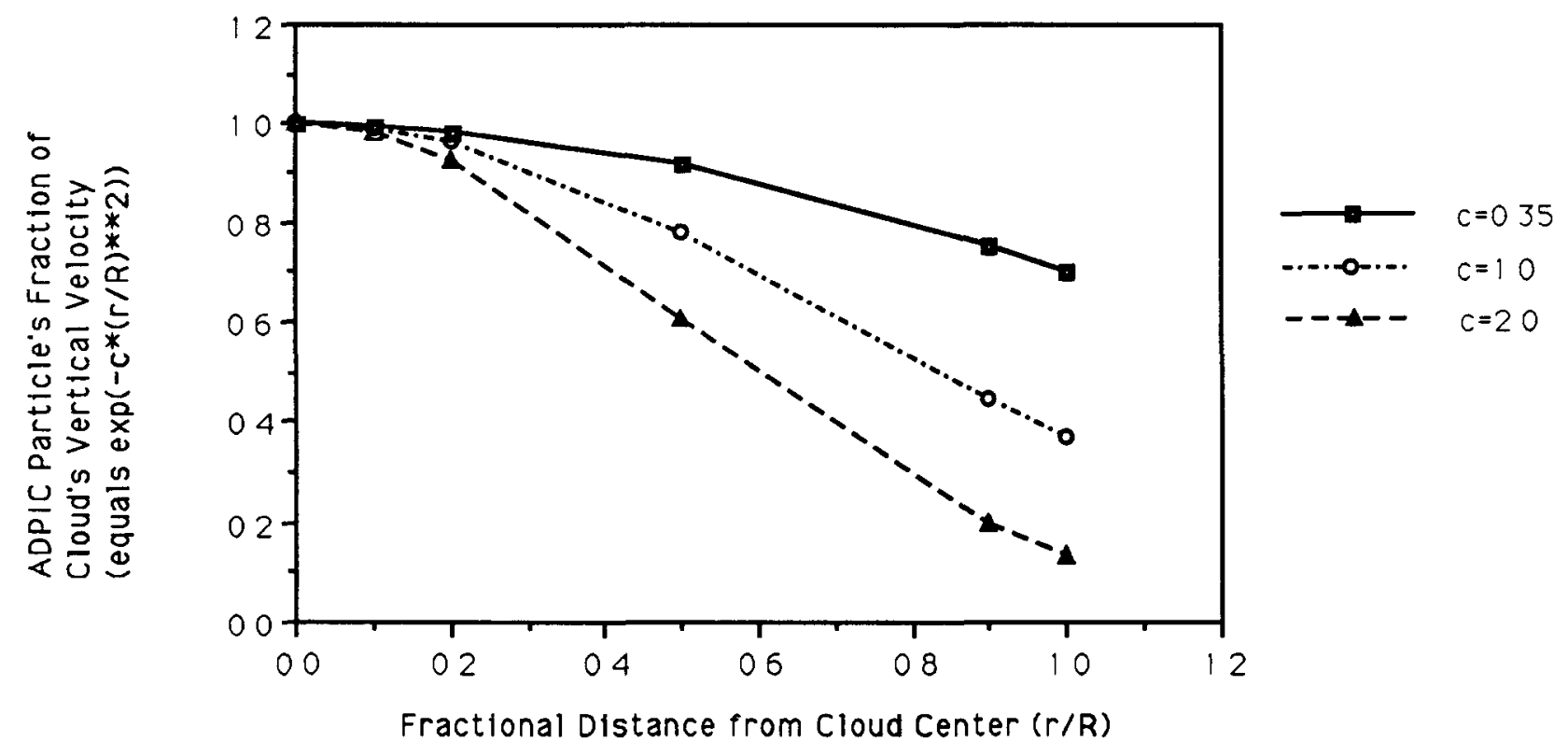

Figure 3: Sensitivity of Cloud to Particle Coupling for Varying Values of $c$, the Coupling Coefficient. 

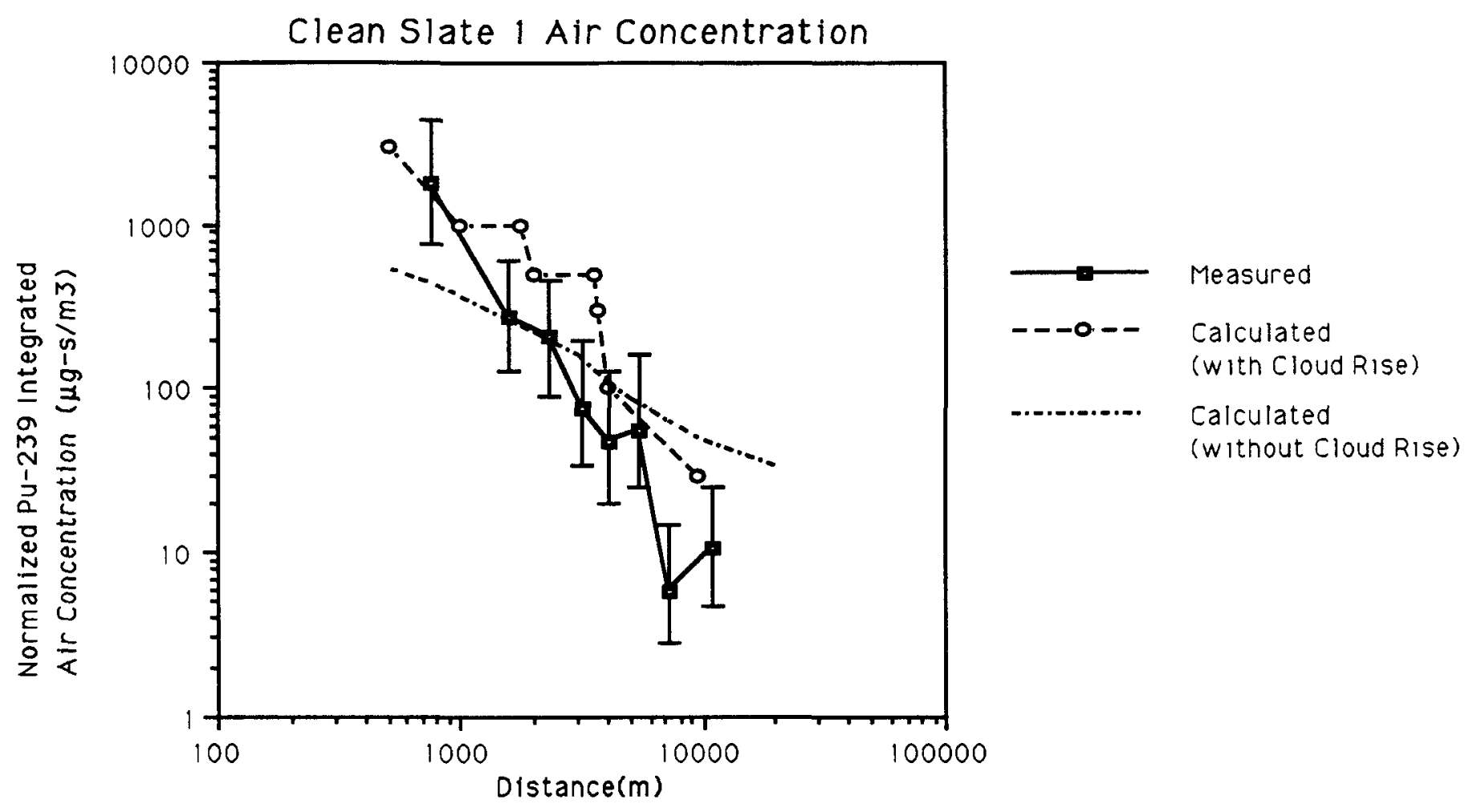

Clean Slate 1 Deposition
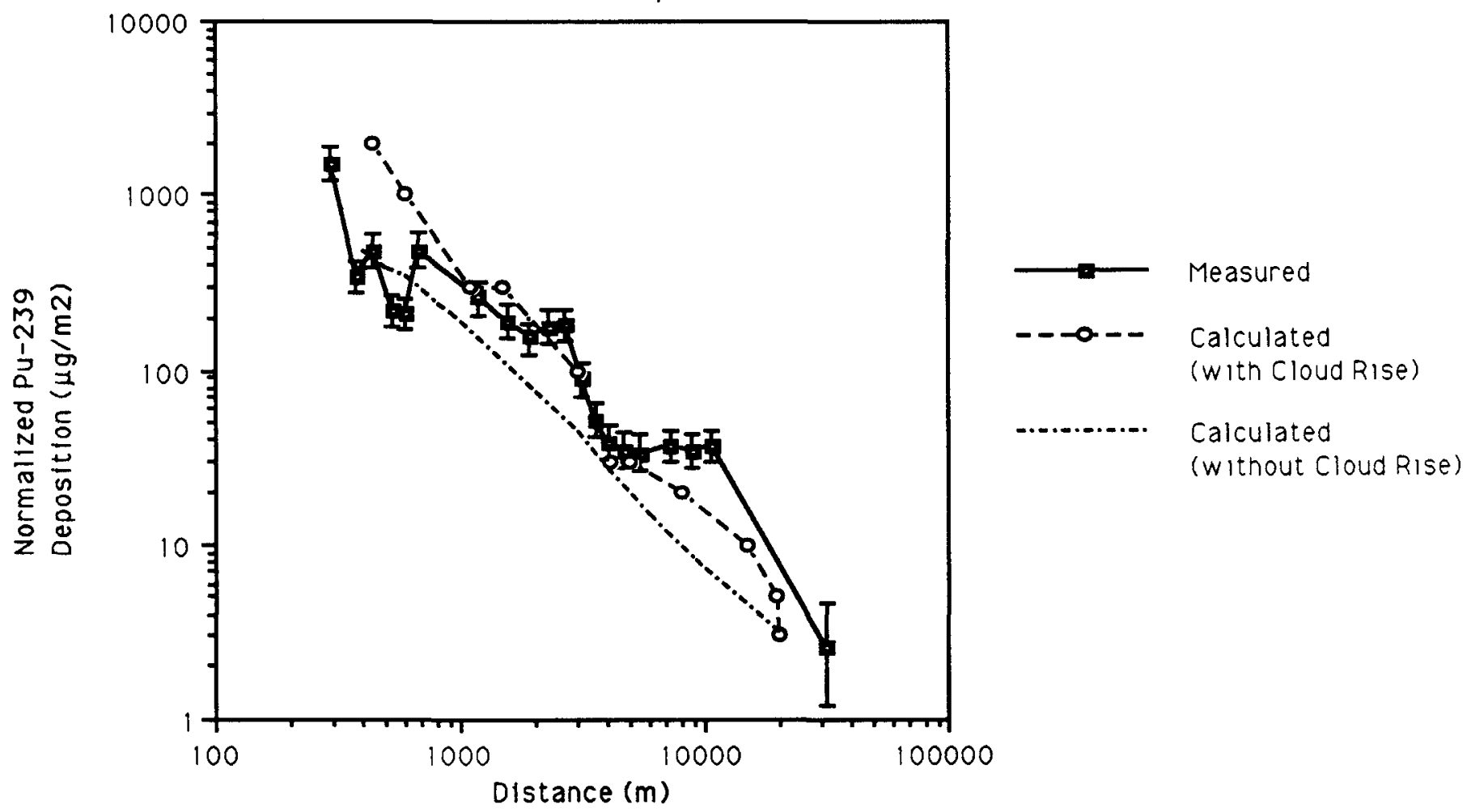

Figure 4 Comparison of Measured, ADPIC Calculations with Cloud Rise, and ADPIC Calculations without Cloud Rise (Gudiksen, et al (5)) for Clean Slate 1 Air Concentration and Deposition Data 

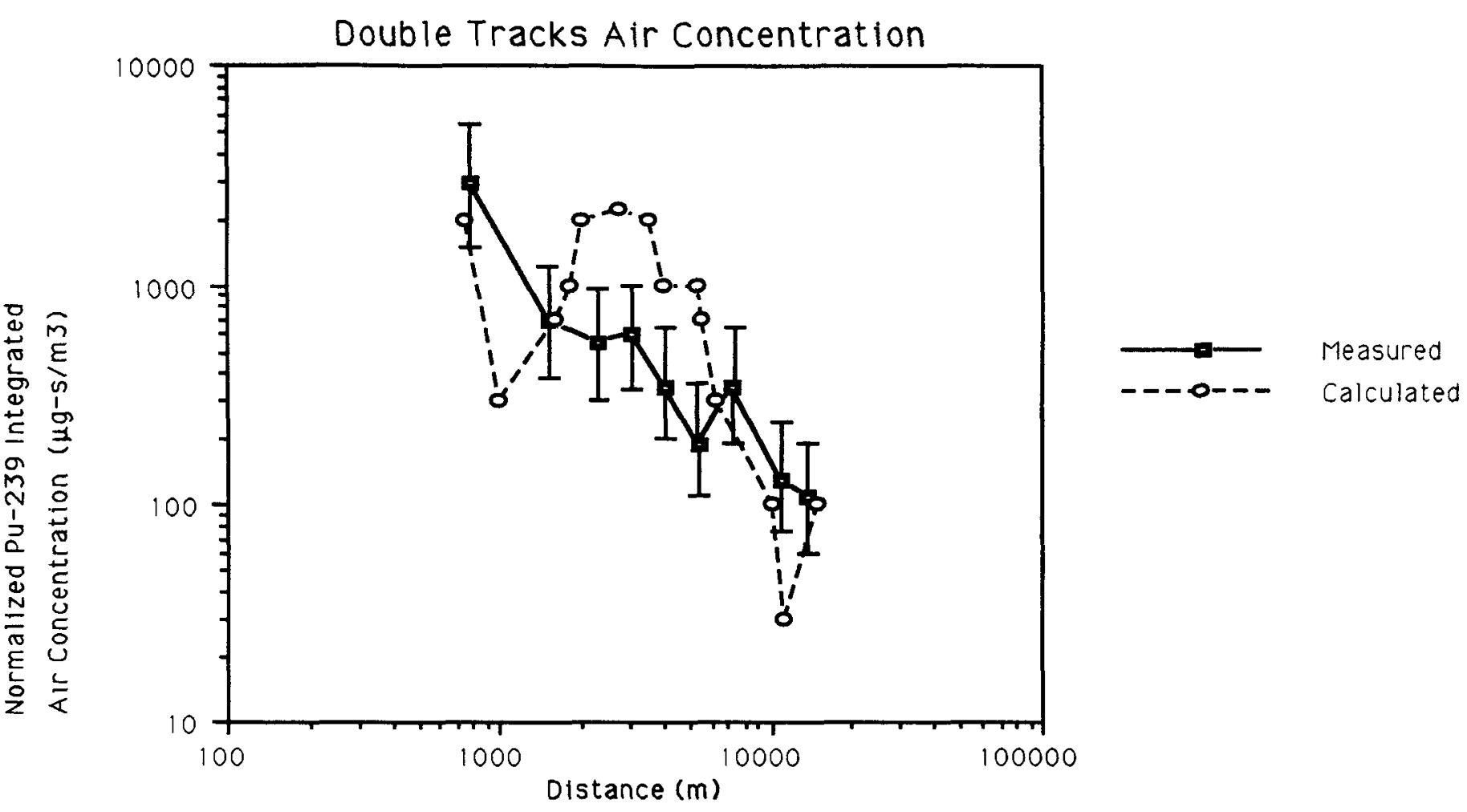

Double Tracks Deposition
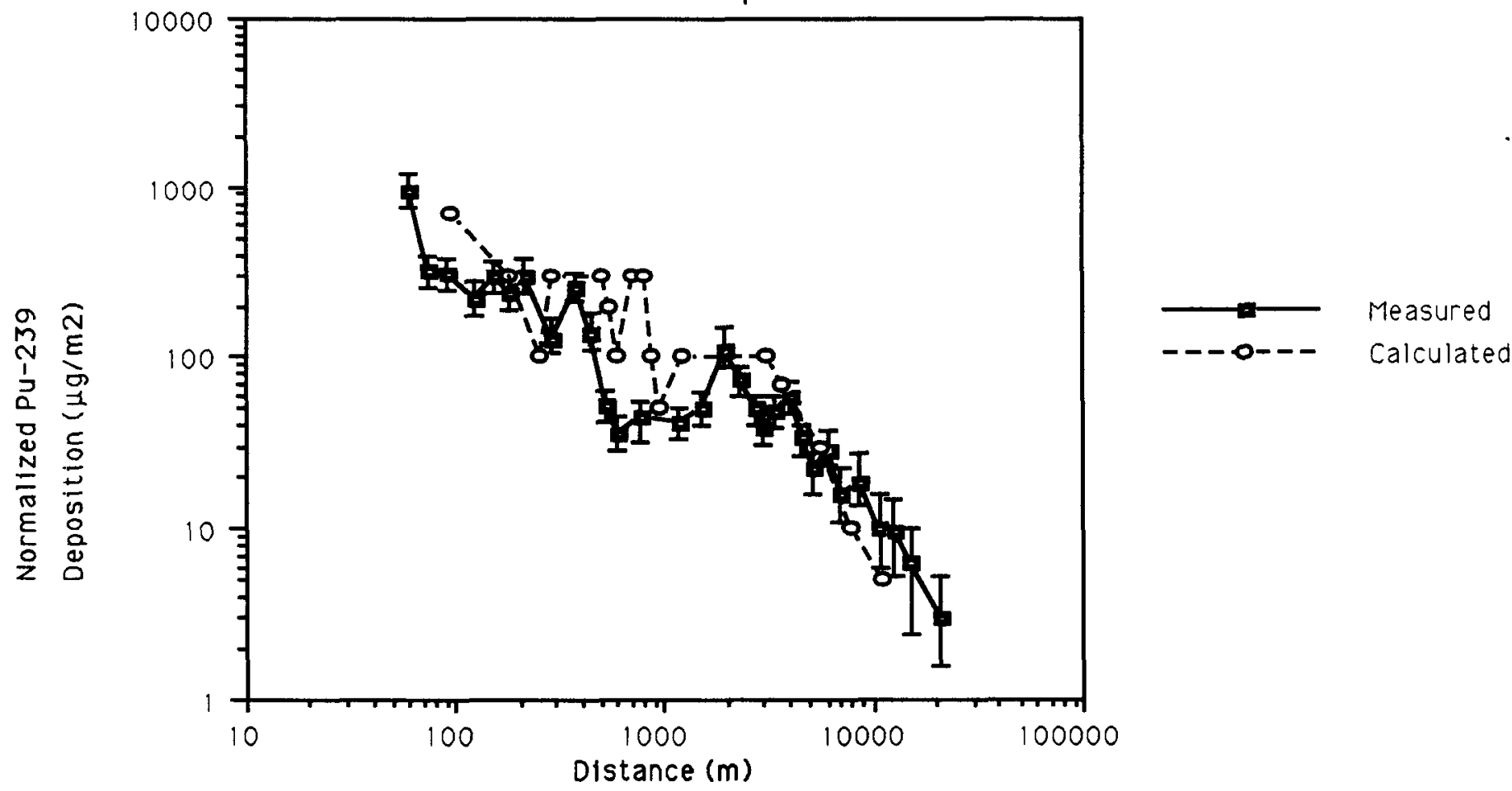

Figure 5 Comparison of Measured and ADPIC Calculated Double Tracks Air Concentration and Deposition Data 


\section{Clean Slate 1 Model Parameters}

Grid/Grid Cell

$X, Y$

$20 \mathrm{~km} / 500 \mathrm{~m}$

$Z$

$700 \mathrm{~m} / 50 \mathrm{~m}$

Particle Size

Median Diameter

$40 \mu \mathrm{m}$

Minimum Diameter

$02 \mu \mathrm{m}$

Maximum Diameter

$1000 \mu \mathrm{m}$

Stand Geometric Dev

44

Cloud Rise

High Explosive Amount

$482 \mathrm{~kg}$ (TNT Equivalent)

Table 1 Key ADPIC Parameters

Used in Clean Slate 1

Validation Studies

\section{Double Tracks Model Parameters}

Grid/Grid Cell

$X, Y$

Z

Particle Size

Median Diameter

Minımum Diameter

Maximum Diameter

Stand Geometric Dev

Percent of Total Activity

Cloud Rise

High Explosive Amount
$20 \mathrm{~km} / 500 \mathrm{~m}$

$700 \mathrm{~m} / 50 \mathrm{~m}$

$\begin{array}{rlrl}\text { Smaller } & & \text { Larger } & \\ 20 & \mu \mathrm{m} & 250 & \mu \mathrm{m} \\ 02 & \mu \mathrm{m} & 90 & \mu \mathrm{m} \\ 400 & \mu \mathrm{m} & 400 & \mu \mathrm{m} \\ 20 & & 15 & \\ 99 & 1 & \end{array}$

Table 2 Key ADPIC Parameters

Used in Double Tracks

Validation Studies 
级程。
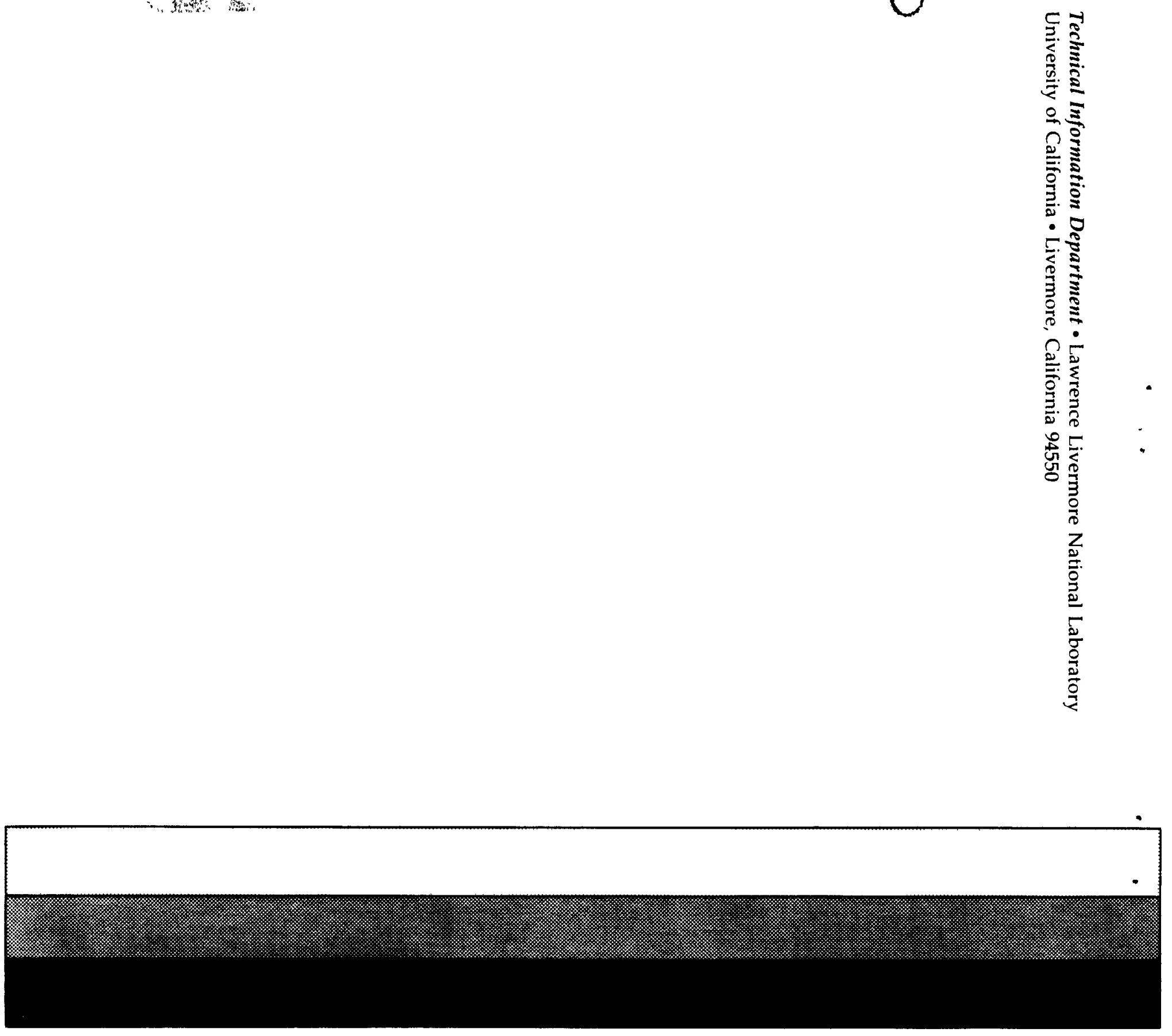